\title{
BIOSTRATIGRAFI DAN ANALISIS PERUBAHAN KEDALAMAN TERMOKLIN DI LEPAS PANTAI BARAT DAYA SUMBA SEJAK PLEISTOSEN AKHIR BERDASARKAN KUMPULAN FORAMINIFERA PLANKTONIK
}

\author{
RYAN DWI WAHYU ARDI ${ }^{1,4}$, KHOIRIL ANWAR MARYUNANI ${ }^{1}$, EKO YULIANTO ${ }^{2}$, \\ PURNA SULASTYA PUTRA ${ }^{2}$, DAN SEPTRIONO HARI NUGROHO ${ }^{3}$
}

1. Program Studi Teknik Geologi, Fakultas Ilmu dan Teknologi Kebumian, Institut Teknologi Bandung (ITB), JL. Ganesha No.10, Bandung, Jawa Barat, Indonesia, 40132, Email: dwa.ryan@ gmail.com

2. Pusat Penelitian Geoteknologi, Lembaga Ilmu Pengetahuan Indonesia, J1. Sangkuriang Bandung 40135

3. Pusat Penelitian Laut Dalam, Lembaga Ilmu Pengetahuan Indonesia, Jl. Y. Syaranamual Ambon 97233

4. Program Studi Agroteknologi, Universitas Nahdlatul Ulama Purwokerto, Jl. Sultan Agung No. 42

Purwokerto 53144

\begin{abstract}
Sari - Foraminifera merupakan mikrofauna/mikrofosil yang sering diaplikasikan dalam geologi terutama untuk analisis biostratigrafi dan paleoekologi. Wilayah lepas pantai barat daya Sumba sangat dipengaruhi oleh pergantian muson barat laut - muson tenggara dan berada di dekat salah satu jalur keluar ITF yaitu Selat Ombai - Laut Sawu yang akirnya berperan besar dalam membentuk kondisi ekologinya. Penelitian ini bertujuan untuk membuat biozonasi dan analisis salah satu parameter ekologi yaitu kedalaman termoklin di wilayah lepas pantai barat daya Sumba berdasarkan kumpulan foraminifera planktonik. Inti sedimen laut dalam sepanjang $235 \mathrm{~cm}$ dengan kode S8 akan digunakan sebagai bahan penelitian..Determinasi foraminifera dilakukan secara kuantitatif dengan mengamati kirakira 300 spesimen dalam satu bagian sampel. Masing-masing takson yang ditemukan pada bagian tersebut dihitung jumlah individunya sedangkan taksa berbeda yang ditemukan di luar bagian tersebut dianggap berjumlah satu. Biozonasi dibuat berdasarkan biozonasi Blow serta biozonasi Bolli dan Saunders. Berdasarkan biozonasi Blow diperoleh satu zona yaitu zona N23 yang setara dengan Pleistosen - Holosen. Sementara berdasarkan biozonasi Bolli dan Saunders diperoleh dua zona yaitu zona Globigerinella calida - Clavarotella bermudezi (di bawah kedalaman $147 \mathrm{~cm}$ ) yang setara Pleistosen Akhir dan zona Globorotalia fimbriata (kedalaman 0 - $147 \mathrm{~cm}$ ) yang setara Holosen. Analisis paleoekologi difokuskan pada parameter kedalaman termoklin yang ditentukan dari kelimpahan relatif taksa thermocline dweller yang terdiri dari Neogloboquadrina dutertrei, Puleniatina obliqueloculata, dan Globorotalia menardii. Selama Pleistosen kelimpahan thermocline dweller relatif lebih tinggi $(49,76-75,66 \%$, rata-rata $60,01 \%)$ yang mengindikasikan pendangkalan termoklin (kondisi eutropik) sedangkan selama Holosen kelimpahannya lebih rendah $(33,90-57,17 \%$, rata-rata $45,77 \%)$ yang mengindikasikan mendalamnya termoklin (kondisi lebih oligotropik). Kondisi tersebut berkaitan dengan dominasi muson tenggara (ITF menguat) selama Pleistosen yang kemudian melemah pada Holosen dan memicu penguatan muson barat laut (ITF melemah).
\end{abstract}

Kata kunci: biostratigrafi, foraminifera, ITF, kedalaman termoklin, muson.

\begin{abstract}
Foraminifera are microfaunas/microfossils that frequently applied in geology especially for biostratigraphy and paleoecological analysis. This research aim to create biozonation and paleoecological analysis in the region off the southwest coast of Sumba based on planktonic foraminiferal assemblages. This region heavily affected by northwest monsoon - southeast monsoon shift and located next to one of the ITF's outflow paths (Ombai Strait - Savu Sea) which eventually form its ecological condition. A $235 \mathrm{~cm}$ long deep sea sediment core coded ST08 will be used as research material. Foraminifera specimens were determined quantitatively by observing approximately 300 specimens for each split. Each taxon determined from that part then calculated for each individu that was found while different taxa determined from other splits are considered to be one. Biozonation was determined based on either Blow biozonation or Bolli and Saunders biozonation. One zone was obtained based on Blow biozonation which is N23 zone, equal to Pleistocene - Holocene. Two zones were determined based on Bolli and Saunders biozonation which are Globigerinella calida - Clavarotella bermudezi zone (below $147 \mathrm{~cm}$ depth), equal to Late Pleistocene and Globorotalia fimbriata zone (0-147 cm depth), equal to Holocene. Paleocological analysis focused on the thermocline depth parameter inferred from the relative abundance of thermocline dweller taxa that consist of Neogloboquadrina dutertrei, Puleniatina obliqueloculata, and Globorotalia menardii. Themocline dweller abundance were relatively higher during Pleistocene $(49,76-75,66 \%$, average 60,01\%), indicating shallower thermocline (eutropic condition) while during Holocene its abundance relatively lower (33,90 - 57, 17\%, average
\end{abstract}


45,77\%), which indicated thermocline deepening (more oligotropic condition). Those conditions were related to the southeast monsoon domination during Pleistocene (stronger ITF) before its weakening on Holocene which induced northwest monsoon strengthening (weaker ITF).

Keywords: biostratigraphy, foraminifera, ITF, monsoon, thermocline depth

\section{PENDAHULUAN}

Foraminifera merupakan mikrofauna laut dan termasuk dalam Kingdom Protista yang sering dipelajari dalam geologi karena pengaplikasiannya yang cukup mudah terutama dalam studi stratigrafi (biostratigrafi) dan paleoekologi. Dalam geologi foraminifera yang diamati terdapat pada sedimen atau batuan sedimen dan hanya menyisakan bagian cangkangnya yang bahkan umumnya telah memfosil. Foraminifera ada yang hidup melayang pada kolom air (planktonik) dan ada pula yang hidup pada substrat di dasar laut (bentonik). Penelitian ini akan difokuskan pada analisis kumpulan foraminifera planktonik.

Foraminifera planktonik memiliki resolusi biostratigrafi yang cukup tinggi selama Neogen sehingga sering diaplikasikan untuk membuat biozonasi sedimen/batuan sedimen laut (Blow, 1969, 1970; Bolli dan Saunders, 1985). Selain itu mikrofauna ini juga memiliki sensitivitas yang tinggi terhadap perubahan lingkungan sehingga sering digunakan sebagai proksi pada penelitian tentang paleokologi, paleoklimatologi, maupun paleo-oseanografi. Dalam hal ini parameter paleokologi yang paling mudah dideteksi dari kelimpahan foraminifera planktonik adalah stratifikasi air laut (kedalaman termoklin) yang akan menjadi fokus pada penelitian ini bersama dengan analisis biostratigrafi. Dalam hal ini mendangkalnya kedalaman termoklin dapat ditunjukkan oleh meningkatnya peningkatan kelimpahan relatif taksa thermocline dweller, sedangkan mendalamnya kedalaman termoklin tercermin dari penurunan kelimpahan relatifnya. Thermocline dweller merupakan taksa foraminifera planktonik yang cenderung hidup di sekitar lapisan termoklin dan akan sangat melimpah pada kondisi eutropik yang membentuk lapisan Deep Chlorophyll Maximum (DCM) akibat kedalaman termoklin yang mencapai kedalaman light compensation (Spooner dkk., 2005).

Penelitian akan dilakukan terhadap inti sedimen S8 yang diambil di lepas pantai barat daya Sumba pada kedalaman $2.966 \mathrm{~m}$ (batial) (Pusat Penelitian Oseanografi LIPI, 2006) (Gambar 1). Wilayah ini memiliki kondisi iklim yang sangat dipengaruhi oleh pergantian muson barat laut - muson tenggara yang terlihat dari curah hujan yang sangat kontras pada musim kemarau dan musim penghujan (Aldrian dan Susanto, 2003; Mohtadi dkk., 2007). Salah satu jalur keluar Indonesian Through Flow (ITF) yaitu Selat Ombai - Laut Sawu juga berada di dekat daerah penelitian sehingga penelitian ini diharapkan dapat membaca fluktuasinya di masa lampau (Hautala dkk., 1996; Gordon, 2005; Spooner dkk., 2005). Dalam hal ini belum pernah dilakukan penelitian khusus terhadap kedalaman termoklin di wilayah lepas pantai barat daya Sumba padahal wilayah ini tidak tepat berada di jalur keluar ITF (Gambar 2) sehingga seberapa besar pengaruhnya terhadap kondisi ekologi daerah penelitian menjadi topik yang menarik untuk dibahas. 


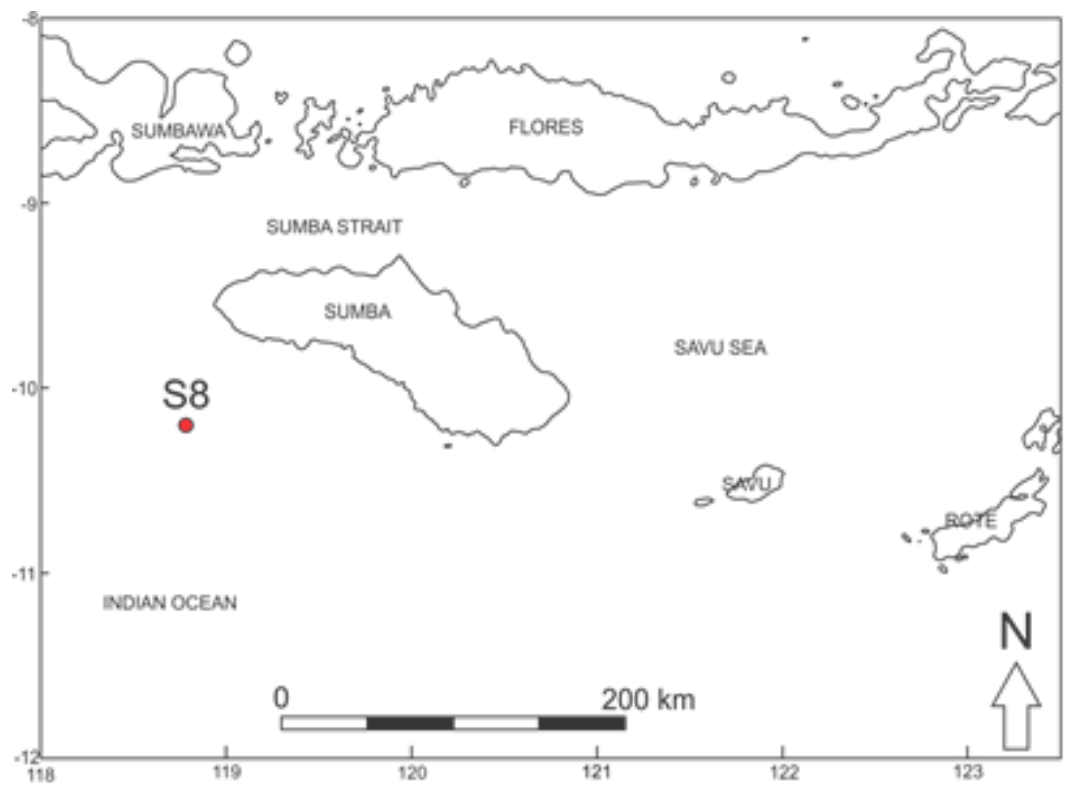

Gambar 1. Daerah penelitian, S8 (titik merah) merupakan lokasi pengambilan inti sedimen yang diteliti (Pusat Penelitian Oseanografi LIPI, 2016).

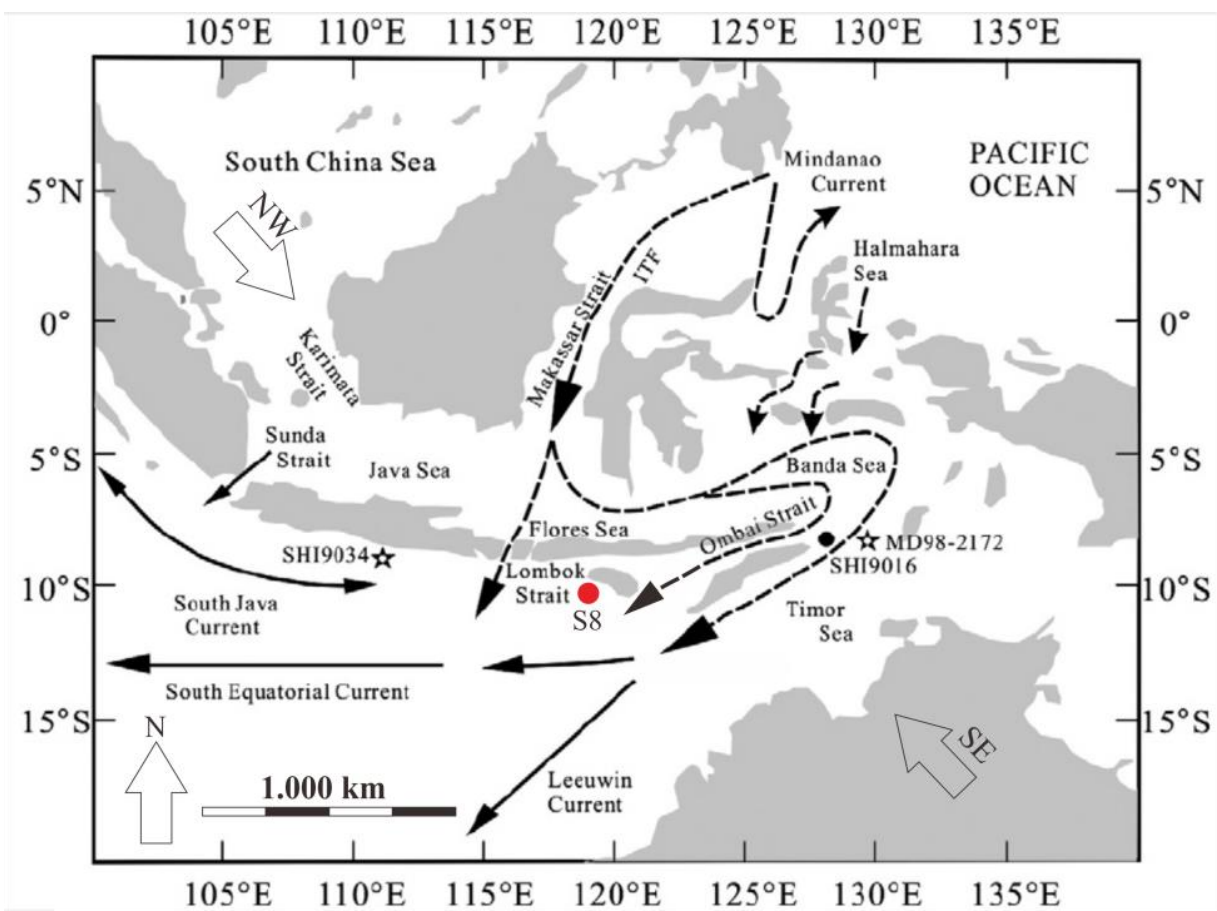

Gambar 2. ITF (garis putus-putus) beserta aliran-aliran lain yang berasosiasi dengannya (Ding dkk., 2013), lokasi pengambilan inti sedimen S8 ditandai dengan bulatan merah.

\section{DATA DAN METODE PENELITIAN}

\subsection{Data}

Data pada penelitian ini berupa sampelsampel sedimen yang diambil dengan interval $2 \mathrm{~cm}$ dari inti sedimen yang memiliki panjang $236 \mathrm{~cm}$ (inti S8). Inti sedimen tersebut diambil pada Ekspedisi Widya Nusantara (E-WIN) yang dilaksanakan oleh Pusat Penelitian Oseanografi LIPI pada Agustus 2016.

\subsection{Metode Penelitian}

\subsubsection{Preparasi}

Pertama-tama dilakukan penimbangan terhadap masing-masing sampel (diambil 5 g) Setelah itu dilakukan preparasi dengan 
merendam masing-masing sampel pada bejana berisi larutan $\mathrm{H}_{2} \mathrm{O}_{2} 5 \%$ selama $3-6$ jam. Kemudian masing-masing sampel dicuci dan disaring di atas saringan berukuran 30, 80, dan 100 mesh $(0,5 ; 0,177$; dan $0,149 \mathrm{~mm})$. Residu pada saringan berukuran 80 dan 100 mesh lalu dipanaskan dengan oven pada suhu $60^{\circ} \mathrm{C}$ hingga cukup kering. Setelah melalui langkah-langkah tersebut maka sampel siap untuk dideterminasi.

\subsubsection{Determinasi Kuantitatif}

Determinasi kuantitatif dilakukan dengan terlebih dahulu membagi (splitting) sampel hingga pada satu bagian diperkirakan terdapat 300 spesimen foraminifera. Kemudian pada bagian tersebut masingmasing takson yang teridentifikasi dihitung jumlahnya. Selain itu dilakukan pengamatan pada bagian-bagian lain untuk mencari taksa yang belum hadir dan kemudian dihitung berjumlah satu spesimen.

Setelah itu dilakukan normalisasi terhadap jumlah pembagian dan berat sampel dengan persamaan sebagai berikut:

$$
\begin{aligned}
& \text { a. Normalisasi jumlah pembagian (split) } \\
& \qquad N=2^{\mathrm{n}} \times A
\end{aligned}
$$

dengan:

$\mathrm{A}=$ jumlah spesimen spesies $\mathrm{X}$ pada satu bagian yang dianalisis

$\mathrm{n}=$ jumlah split

$\mathrm{N}=$ jumlah spesimen spesies $\mathrm{X}$ pada satu sampel utuh

b. Normalisasi berat

Juml. akhir spesimen spesies $\mathrm{X}=$

$$
\frac{\text { Berat ditimbang }}{\text { Berat diharapkan }} \times \mathrm{N}
$$

Hasil normalisasi kemudian disajikan pada tabel distribusi (Gambar 3).

\subsubsection{Pengolahan dan Analisis Data}

Analisis biostratigrafi dilakukan dengan pembuatan biozonasi berdasarkan kehadiran dan kemunculan taksa foraminifera pada biozonasi yang dibuat oleh Blow (1969, 1970) serta Bolli dan Saunders (1985). Sementara itu analisis paleoekologi difokuskan pada kedalaman termoklin (mencerminkan stratifikasi air laut) dengan melihat kelimpahan relatif taksa thermocline dweller. Taksa foraminifera yang tergolong thermocline dweller dan akan dianalisis kelimpahannya terdiri dari Neogloboquadrina dutertrei, Pulleniatina obliqueloculata, dan Globorotalia menardii (Barmawidjaja dkk., 1993; Baohua dkk., 1997; Spooner dkk., 2005; Ding dkk., 2006; Sijinkumar dkk., 2011).

\section{HASIL DAN DISKUSI}

\subsection{Biostratigrafi}

\subsubsection{Biozonasi Blow}

Berdasarkan biozonasi foraminifera planktonik menurut Blow $(1969,1970)$ inti S8 hanya terdiri dari satu zona yaitu zona N23. Zona ini ditandai dengan kehadiran Globigerinella calida pada interval terbawah $(234-235 \mathrm{~cm})$. Zona N23 memiliki umur yang setara dengan Pleistosen - Holosen (Gambar 4).

\subsubsection{Biozonasi Bolli dan Saunders}

Berdasarkan biozonasi foraminifera planktonik lintang rendah menurut Bolli dan Saunders (1985) sedimen pada inti S8 terdiri dari dua zona. Dua zona tersebut adalah zona Globigerinella calida Clavarotella bermudezi (di bawah kedalaman $147 \mathrm{~cm}$ ) dan zona Globorotalia fimbriata (interval $0-147 \mathrm{~cm}$ ). Zona Globigerinella calida - Clavarotella bermudezi ditandai oleh kehadiran Globigerinella calida pada bagian bawah sedangkan batas atasnya ditandai oleh kemunculan awal Globorotalia fimbriata, setara dengan Pleistosen Akhir. Sementara itu zona Globorotalia fimbriata dibatasi oleh kemunculan Globorotalia fimbriata di bagian bawah yang menandai dimulainya Kala Holosen (Gambar 2).

\subsection{Paleoekologi: Kedalaman Termoklin}

Kelimpahan relatif thermocline dweller menunjukkan nilai yang cukup kontras 
antara Pleistosen dan Holosen (Gambar 3). Selama Pleistosen kelimpahan thermocline dweller cenderung lebih tinggi (49,76 $75,66 \%$, rata-rata $60,01 \%)$ yang mengindikasikan adanya pendangkalan termoklin (kondisi eutropik). Sementara itu kelimpahan thermocline dweller cenderung menurun pada Holosen $(33,90-57,17 \%$, rata-rata $45,77 \%$ ) yang mengindikasikan mendalamnya termoklin atau kondisi air laut menjadi lebih oligotropik (kedalaman termoklin di bawah kedalaman light compensation).

Pendangkalan termoklin selama Pleistosen kemungkinan berhubungan dengan dominasi muson tenggara (Wyrwoll dan Miller, 2001; Spooner dkk., 2005; Ding dkk., 2013). Dominasi muson tenggara tersebut disebabkan oleh posisi InterTropical Convergence Zone (ITCZ) selama musim panas belahan bumi selatan (Austral summer) yang berada si atas Pulau Jawa, Laut Flores, hingga Laut Banda sehingga muson barat laut tidak dapat mencapai wilayah tenggara Kepulauan Indonesia, termasuk daerah penelitian (Spooner dkk., 2005; Xu dkk., 2006; Ding dkk., 2013). Dominasi muson tenggara menyebabkan adanya aliran massa air dingin kaya nutrisi dari tenggara ke Kepulauan Indonesia (van Iperen dkk., 1993; Gordon, 2005; Steinke dkk., 2014). Hal itu mengakibatkan tingginya gradien tekanan antara Samudera Pasifik dan Hindia sehingga ITF menguat (Gordon, 2005; Steinke dkk., 2014). Kehadiran massa air dingin tersebut kemudian turut meningkatkan produktivitas dengan memicu adanya upwelling yang kemudian membuat kedalaman termoklin menjadi lebih dangkal (kondisi eutropik) (van Iperen dkk., 1993; Spooner dkk., 2005).

Memasuki Holosen posisi Austral summer ITCZ berpindah ke sekitar wilayah utara Australia sehingga muson barat laut dapat mencapai wilayah tenggara Kepulauan Indonesia, termasuk daerah penelitian sehingga dominasi muson tenggara pun berkurang (Wyrwoll dan Miller, 2001;
Spooner dkk., 2005; Ding dkk., 2013). Menguatnya muson barat laut memicu adanya aliran massa air rendah salinitas yang melalui Laut Jawa dan Laut Flores menuju ke arah timur yaitu Laut Banda sehingga mengurangi gradien tekanan antara Samudera Pasifik dan Samudera Hindia (Wyrtki, 1987). Berkurangnya gradien tekanan antara Samudera Pasifik dan Hindia berakibat pada melemahnya ITF dan pendalaman termoklin (Gordon, 2005; Steinke dkk., 2014). Kehadiran massa air rendah salinitas tersebut mempengaruhi stratifikasi air laut di wilayah timur Kepulauan Indonesia termasuk daerah penelitian yaitu dengan memperdalam lapisan termoklin (kondisi menjadi lebih oligotropik) (Spooner dkk., 2005; Ding dkk., 2013).

\section{KESIMPULAN}

Dengan menggunakan biozonasi Bolli dan Saunders (1985), batas Pleistosen Holosen inti S8 berhasil dideterminasi yaitu pada interval kedalaman $146-147 \mathrm{~cm}$. Batas ini ditandai dengan kemunculan awal Globorotalia fimbriata. Kehadiran Globigerinella calida pada interval terbawah menunjukkan Zona N23 menurut biozonasi Blow $(1969$, 1970) sehingga dapat disimpulkan bahwa sedimen pada inti S8 diendapkan sejak Pleistosen Akhir. Analisis berdasarkan kelimpahan relatif taksa thermocline dweller menunjukkan adanya perbedaan kedalaman termoklin antara Pleistosen dan Holosen. Kedalaman termoklin selama Pleistosen relatif dangkal yang diakibatkan oleh dominasi muson tenggara (memicu pembentukan upwelling) dan kuatnya intensitas ITF, sedangkan selama Holosen kedalaman termoklin lebih dalam akibat menguatnya muson barat laut dan ITF. Perbedaan kedalaman termoklin tersebut menunjukkan bahwa wilayah lepas pantai barat daya Sumba masih dipengaruhi oleh ITF walau tidak berada tepat di jalur keluar ITF, dalam hal ini fluktuasi ITF berkaitan erat dengan fluktuasi intensitas muson akibat pergeseran posisi Austral summer ITCZ. 


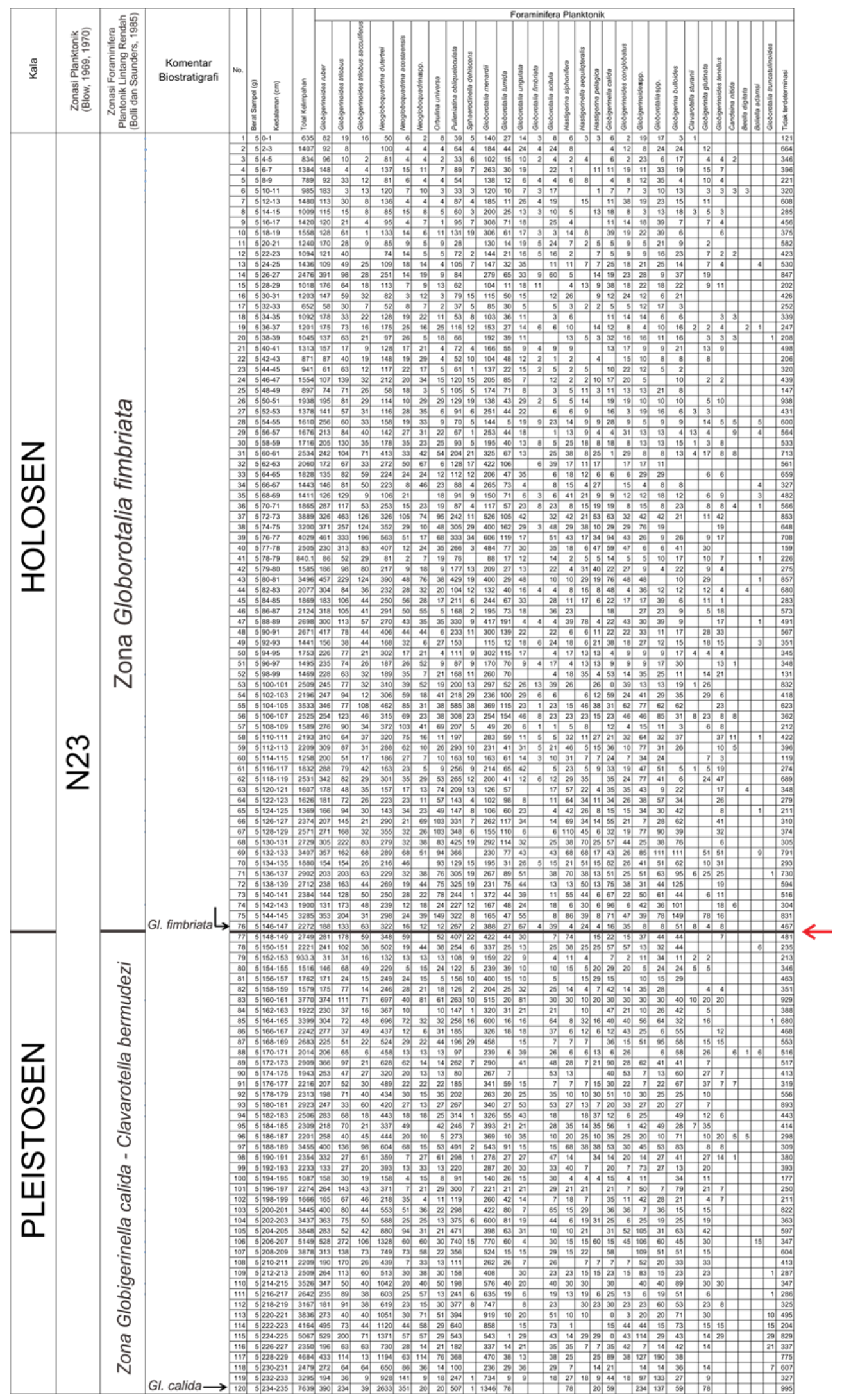

Gambar 3. Tabel distribusi dan biozonasi inti sedimen S8. 

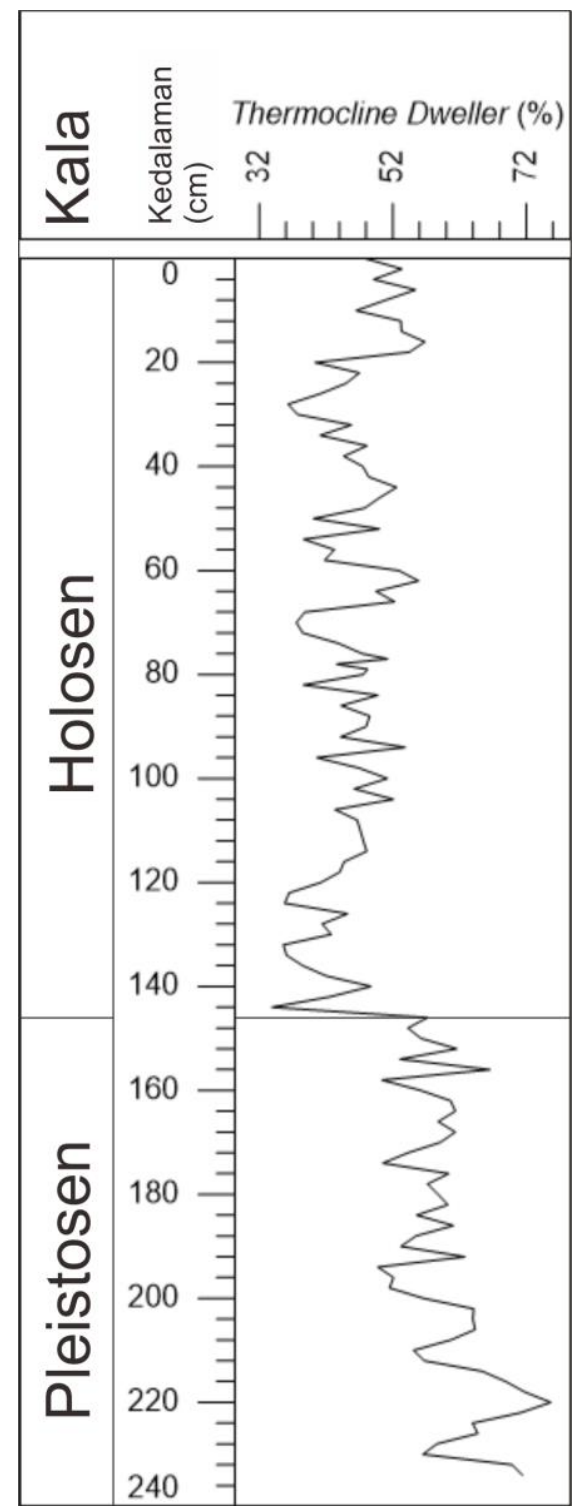

Gambar 4 Kelimpahan relatif thermocline dweller pada inti sedimen S8 yang mengindikasikan kedalaman termoklin.

\section{UCAPAN TERIMAKASIH}

Penulis sangat berterima kasih kepada Pusat Penelitian Oseanografi LIPI khususnya Udhi Hermawan, Ph.D. selaku chief scientist EWIN 2006 atas izin penggunaan data yang diberikan, Singgih Prasetyo Adi Wibowo selaku teknisi beserta nahkoda dan seluruh anak buah kapal riset Baruna Jaya VIII atas bantuan selama pengambilan data, Pusat Penelitian Geoteknologi LIPI dan Program Studi Teknik Geologi ITB atas fasilitas laboratorium, serta Lembaga Pengelola Dana Pendidikan (LPDP) atas bantuan dana penelitian yang diberikan kepada Ryan Dwi

\section{Wahyu Ardi (No. kontrak : 20160611017188). \\ REFERENSI}

Aldrian, E. dan Susanto, R.D., 2003. Identification of three dominant rainfall regions within Indonesia and their relationship to sea surface temperature, International Journal of Climatology 23, 1435 - 1452. doi: 10.1002/joc. 950

Baohua, L., Zhimin, J., dan Pinxian, W., 1997. Pulleniatina obliquiloculata as a paleoceanographic indicator in the southern Okinawa Trough during the last 20,000 years, Marine Micropaleontology 32, 59-69.

Barmawidjaja, B.M., Rohling, E.J., van der Kaars, W.A., Vergnaud Grazzini, C., dan Zachariasse, W.J., 1993. Glacial conditions in the northern Moluccas Sea region (Indonesia), Palaeogeography, Palaeoclimatology, Palaeoecology 101: 147-167.

Blow, W.H., 1969. Late Middle Eocene to Recent planktonic foraminiferal Biostratigraphy dalam Bronnimann, R. \& Renz, H. H., 1967, ed., Proceedings of the First International Conference on Planktonic Microfossils 1, 199 421, Geneva.

Blow, W. H., 1970. Validity of biostratigraphic correlations based on the Globigerinacea, Micropaleontology 16, 257 - 268.

Bolli, H.M. dan Saunders, J.B., 1985. Oligocene to Holocene low latitude planktic foraminifera dalam Bolli, $\mathrm{H}$. M., Saunders, J. B., dan Perch Nielsen, K., 1985, ed., Plankton stratigraphy, Vol I, 155 - 262, Cambridge University Press, Cambridge.

Ding, X., Bassinot, F., Guichard, F., Li, Q. Y., Fang, N. Q., Labeyrie, L, Xin, R. C., Adisaputra, M. K., dan Hardjawidjaksana, K., 2006. Distribution and ecology of planktonic foraminifera from the seas around the 
Indonesian Archipelago, Marine Micropaleontology 58, 114 - 134.

Ding, X., Bassinot, F., Guichard, F., dan Fang, N. Q., 2013. Indonesian Throughflow and monsoon acyivity record in The Timor Sea since the last glacial maximum. Marine Micropaleontology 101, $115 \quad-\quad 126 . \quad$ doi: 10.1016/j.marmicro.2013.02.003

Gordon, A. L., 2005. Oceanography of the Indonesian Seas and Their Throughflow, Oceanography 18 (4), 14 $-27$.

Hautala, S.L., Reid, J.L., dan Bray, N., 1996. The distribution and mixing of Pacific water masses in the Indonesian Seas, Journal of Geophysical Research 101, $12.375-12.389$.

Mohtadi, M., Max, L., Hebbeln, D., Baumgart, A., Kruck, N., dan Jennerjahn, T., 2007. Modern environmental conditions recorded in surface sediment samples off $\mathrm{W}$ and SW Indonesia: Planktonic foraminifera and biogenic compounds analyses, Marine Micropaleontology 65, $\quad 96 \quad-\quad 112$. doi:10.1016/j.marmicro.2007.06.004

Pusat Penelitian Oseanografi LIPI, 2016. Laporan Akhir Ekspedisi Widya Nusantara 2016, 10 - 69 (Tidak dipublikasikan).

Sijinkumar, A.V., Nagender Nath, B., Possnert, G., dan Aldahan, A., 2011. Pulleniatina minimum events in the Andaman Sea (NE Indian Ocean): implications for winter monsoon and thermocline changes, Marine Micropaleontology 81, 88 94.

doi:10.1016/j.marmicro.2011.09.001

Spooner, M.I, Barrows, T.T, De Deckker, P., doi:10.1016/j.marmicro.2005.10.003

dan Paterne, M., 2005. Palaeoceanography of the Banda Sea, and Late Pleistocene initiation of the Northwest Monsoon, Global and Planetary Change 49, 28 - 46. doi:10.1016/j.gloplacha.2005.05.002

Steinke, S., Prange, M., Feist, C., Groeneveld, J., dan Mohtadi, M., 2014. Upwelling variability off southern Indonesia over the past two millennia, Geophysical Research Letter 41, 7684 - 7693. doi:10.1002/2014GL061450.

van Iperen, J.M., van Bennekom, A.J., dan van Weering, T.C.E., 1993. Diatoms in surface sediments of the Indonesian Archipelago and their relation to hydrography, Hydrobiologia 269/270, $113-128$.

Wyrtki, K., 1987. Indonesian Throughflow and the associated pressure gradient, Journal of Geophysical Research 92, 12941- 12946.

Wyrwoll, K. H. dan Miller, G. H., 2001. Initiation of the Australian summer monsoon 14,000 years ago, Quaternary International 83-85, 119- 128.

Xu, J., Kuhnt, W., Holbourn, A., Andersen, N., dan Bartolli, G. (2006): Changes in the vertical profile of the Indonesian Throughflow during Termination II: Evidence from the Timor Sea, Paleoceanography, 21, 4202. doi:10.1029/2006PA001278 